\title{
Clinical, Biochemical, Therapeutic, and Complication Strategy of High-Altitude Pulmonary Edema: Update from Western Himalayas
}

\author{
Krishan Singh, Santosh Kumar Singh', Vani Singh², Ajai Kumar Tentu ${ }^{3}$, A. K. Naik ${ }^{4}$, Nidhi Singh ${ }^{5}$, Gaurav Joshii ${ }^{6}$ \\ High Altitude Medical Research Center, LEH, 153 General Hospital, Ladakh, ${ }^{1}$ Department of Medicine, Command Hospital, Udhampur, ${ }^{2}$ MOIC, ECHS, Udhampur, Jammu \\ \&Kashmir, ${ }^{3}$ Department of Pulmonology, Army Institute of Cardiothoracic Sciences (AICTS), Affiliated to Armed Forces Medical College (AFMC), Pune, ${ }^{4} \mathrm{Hospital}$ \\ Administration, Brig Med 14 Corps, ${ }^{5}$ Medical Officer, 153 General Hospital, LEH, ${ }^{6}$ MBBS Student, Atal Bihari Vajpayee Institute of Medical Sciences, New Delhi
}

\section{Abstract}

Introduction: People traveling to high altitudes (HAs) for work or pleasure are increasing day by day. The rewards of such travel are generally at the risk of developing of acute altitude illnesses and/or worsening of underlying medical problems. The present study was undertaken in a hospital at 11,500 feet to get updated information on the wide clinical spectrum of patients of high-altitude pulmonary edema (HAPE). Patients and Methods: The study was carried out at a general hospital located at 11,500 feet. The total number of study participants was 151 . They were divided into two groups: those who were entering HA for the first time were 17 participants and those who had spent several months at HA 134 patients. All patients in the second group had been completely acclimatized before going down to sea level. The Lake Louis Criteria were taken as the basis for the diagnosis of HAPE. Results: Pulmonary edema was the most common serious illness seen at HA. Majority of the patients presented at 72-96 h after induction to HA. The common symptoms were breathlessness, cough, and headache at rest. In addition, all patients complained to a varying extent of one or more of the following symptoms: dyspnea, cough, fever, chest pain, dizziness, etc., The majority of the patients showed leukocytosis. Pneumonitis may be a predisposing factor or develop secondary to pulmonary edema. Conclusion: Pulmonary edema was the most common serious illness seen at HA. The common symptoms were breathlessness, cough, and headache at rest. The understanding of HAPE has changed since its emergence in the field of diagnosis, pathophysiology, complications, and therapeutic modalities.

Keywords: High altitude, oxygen saturation, pulmonary edema

\section{INTRODUCTION}

There is an increase in the number of people traveling to high altitudes (HAs) either for work or pleasure. The rewards of such travel are generally in the form of risk of developing acute altitude illnesses or worsening of underlying medical problems. The purpose of physiology in medicine is to provide scientific information that can be used as a basis for counseling patients for these purposes. It has been seen that the symptoms of HA pulmonary edema (HAPE) ordinarily happen a few days after landing in height, and it involves dyspnea with exertion, advancing to dyspnea at rest, a dry cough, weakness, and poor exercise tolerance. ${ }^{[1]}$ If the disease worsens without treatment, severe dyspnea and frank pulmonary edema are obvious, with coma and death following. Early clinical signs of the condition include tachycardia and tachypnea, mild

\begin{tabular}{|l|l|}
\hline \multicolumn{2}{|c|}{ Access this article online } \\
\hline Quick Response Code: & Website: \\
\hline & www.ijrc.in \\
\cline { 2 - 2 } & \\
\hline
\end{tabular}

pyrexia, basal crepitations, and dependent edema. In addition, patients generally have decreased oxygen saturation than unaffected people, but the degree of desaturation by itself has not been taken as the reliable sign of HAPE. ${ }^{[2]}$ HAPE rarely occurs below $2500 \mathrm{~m}$. Generally, residents of low altitudes are susceptible to HAPE if acutely exposed to HA. Some suffer

Address for correspondence: Prof. Ajai Kumar Tentu, Department of Pulmonology, Army Institute of Cardio Thoracic Sciences Affiliated to Armed Forces Medical College, Golibar Maidan, Pune - 411040 Maharashtra, India. E-mail: drtentu@gmail.com

This is an open access journal, and articles are distributed under the terms of the Creative Commons Attribution-NonCommercial-ShareAlike 4.0 License, which allows others to remix, tweak, and build upon the work non-commercially, as long as appropriate credit is given and the new creations are licensed under the identical terms.

For reprints contact: WKHLRPMedknow_reprints@wolterskluwer.com

How to cite this article: Singh K, Singh SK, Singh V, Tentu AK, Naik AK, Singh N, et al. Clinical, biochemical, therapeutic, and complication strategy of high-altitude pulmonary edema: Update from Western Himalayas. Indian J Respir Care 2021;10:35-40.

Received: 27-07-2020 Accepted: $19-11-2020$

Revised: 16-09-2020 Published: 31-01-2021 
from HAPE during the first exposure to HA, while others remain unaffected and acclimatize well. The reported incidence of HAPE varies with altitude, rate of ascent, physical activity, and altitude of residence. The incidence of HAPE among such previously unacclimatized participants has been variously reported to range between about $0.01 \%$ and about $5 \%{ }^{[3,4]}$ Some of the combatants who had flown above $3300 \mathrm{~m}$ had an attack rate of $15 \% \cdot{ }^{[5]}$ Most residents of low altitudes remain healthy on returning to HA after sojourns in the plains, but some suffer from HAPE during the reexposure to hypoxia. ${ }^{[6,7]}$ Sometimes, pulmonary edema can occur after a period of adequate acclimatization at a definite altitude, the reasons for which can be factors such as sleep medicines, ${ }^{[8]}$ unaccustomed exertion, cold, and chest infections, which have not been studied in a controlled manner. The present study was undertaken in a hospital at 11,500 feet to get updated information on the wide clinical spectrum of patients of HAPE.

\section{Patients and Methods}

The study was carried out at a general hospital located at 11,500 feet and received patients from a varied area of mountainous territory with heights ranging between 11,000 and 18,000 feet. A total number of study participants were 151 and were divided into two groups: those who were entering $\mathrm{HA}$ for the first time in their lives were 17 participants and those who had spent several months at HA and were again inducting after staying for sometime in the plains (134 patients). All patients in the second group had been completely acclimatized before going down to sea level. Apart from the local inhabitants, who have been living in the region since birth, the population consists of men coming from all over India and serving for short tenures at HAs. The latter group of the population has lived all their lives in the plains. These groups of persons were recruited as cases for the present study. In addition to hypoxia of HA, these men serving in this area are also exposed to severe cold. Extremes of temperatures in the winter season range between $10^{\circ} \mathrm{C}$ and $-40^{\circ} \mathrm{C}$. The Lake Louis Criteria were taken as the basis for the diagnosis of HAPE: cough, breathlessness, tachycardia, tachypnea, and the presence of crepitations in the chest. Differential diagnosis such as myocardial infarction and other causes of pulmonary edema were excluded by clinical examination and electrocardiographically. Radiological diagnosis was confirmatory. All the study protocols were approved by the institutional ethics committee following the guidelines of the Helsinki Declaration.

\section{Results and Discussion}

\section{Incidence}

Pulmonary edema was the most common serious illness seen at HA, constituting $5 \%-10 \%$ of all admissions to the medical wards. During the period May 2018-May 2019, 151 patients with the condition were admitted to the hospital [Table 1]. It almost always affected persons who had arrived by air, and in 2018-2019, the incidence was 2.3/1000 among this group. The majority of patients acquired the disease at the place where the hospital is situated (11,500 feet). The remaining patients were affected at higher altitudes and were evacuated to the hospital by road or helicopter.

\section{Previous experience of high altitude}

The 151 patients could be divided into two groups: those entering HA for the first time (17 patients) and those who had spent several months at HA and were then inducting again after staying for sometimes in the plains (134 patients). All patients in the second group had been completely acclimatized before going down to sea level.

Majority of the patients presented on the $72-96 \mathrm{~h}$ after induction to HA. Table 1 shows the percentage of patients who presented to the hospital at various days of arrival at HA.

\section{Age and weight}

Almost half the patients were between 21 and 30 years of age. The oldest patient was 54 years and the youngest 18 years. The preponderance of younger patients only reflects the exposed population. The disease affected all types, without any predilection for the obese. The heaviest patient weighed $100 \mathrm{~kg}$ and the lightest $57 \mathrm{~kg}$ as illustrated in Table 2.

\section{Symptomatology}

The common symptoms were breathlessness, cough, and headache at rest. In addition, all patients complained to a varying extent of one or more of the following symptoms: dyspnea, fever, chest pain, dizziness, nausea, and palpitations

\section{Table 1: Time lag between induction and symptoms}

\begin{tabular}{lc}
\hline Time lag between induction and symptoms & \\
\hline Day of arrival at HA & Percentage \\
\hline $1^{\text {st }}$ & 4 \\
$2^{\text {nd }}$ & 17.6 \\
$3^{\text {rd }}$ & 43.2 \\
$4^{\text {th }}$ & 54 \\
$5^{\text {th }}$ & 8.8 \\
$6^{\text {th }}$ & 6.4 \\
\hline
\end{tabular}

HA: High altitude

Table 2: Age and weight of the participants

\begin{tabular}{lc}
\hline & $\boldsymbol{n}(\%)$ \\
\hline Age (years) & $2(1.32)$ \\
$17-20$ & $77(50.99)$ \\
$21-30$ & $56(37.08)$ \\
$31-40$ & $16(10.59)$ \\
$>40$ & $151(100)$ \\
Total & \\
Weight (kg) & $14(10)$ \\
$51-60$ & $60(46)$ \\
$61-70$ & $45(33)$ \\
$71-80$ & $12(9)$ \\
$81-90$ & $3(2)$ \\
$>90$ &
\end{tabular}


Singh, et al.: High-altitude pulmonary edema: Update from Western Himalayas

as shown in Table 3. The symptoms were not different in the two groups.

\section{Breathlessness}

Breathlessness at rest came on simultaneously with cough. One hundred and twenty-two patients complained of attacks of nocturnal dyspnea during the $48 \mathrm{~h}$ preceding admission to hospital. In spite of their having had a disturbed night, the patients felt distinctly better in the daytime.

\section{Cough}

Cough was one of the earliest symptoms to appear. It was initially dry. Characteristically, it was short and sharp and appeared suppressed. It did not seem to inconvenience the patient much. As the condition advanced, a small quantity of mucoid sputum was expectorated. The frothy pink sputum considered, so characteristic of pulmonary edema was seen in only 39 cases. In only two of them was the picture absolutely typical-large quantities of fluid sputum, thin in consistency and frothy and pink in color, poured out of the throat of the patient, and he appeared too ill even to expectorate as fast as the sputum formed.

\section{Fever}

Thirty patients complained of fever. It was mild to moderate with chills and rigors and was never very high. Other patients did not feel febrile but on recording had mild fever.

\section{Physical signs}

\section{Temperature, pulse, and respiration}

The majority of patients (30) were running a low-grade fever on admission. Tachycardia and tachypnea were also present. In cases of average severity, the findings were typically as follows: Temperature 98.6 - 100.4 degree F (37 - 38 degree C), pulse (100 $120 / \mathrm{min}$ ) and respirations, 30 - 40/min. It was observed in several early cases that tachycardia was often disproportionately marked as compared with the increase in the respiratory rate [Table 4].

\section{Oxygen saturation}

Majority of the patients had low oxygen saturation (below $80 \%$ ) during reporting to the hospital. Four cases showed $\mathrm{SpO}_{2}$ of $50 \%$ and below and one case had 91\%. Lowest $\mathrm{SpO}_{2}$ detected was $40 \%$ in one case as shown in Table 5 .

\section{Mental state}

The majority of patients were mentally clear. Some of them were apathetic to their surroundings and would not answer questions but were conscious enough to assist in the changing of their clothes. They were all obviously dyspneic and coughing incessantly.

\section{Lung signs}

The majority of the patients revealed crepitations in the lungs; few patients had no crepitations but radiological signs of pulmonary edema were seen. There was no relation between the symptoms, crepitations and radiological signs.

\section{Laboratory investigations}

The majority of the patients showed leukocytosis and were neutrophilic in all cases. In some cases, there was marked

\begin{tabular}{lc}
\hline Table 3: Symptoms of the study participants \\
\hline Symptoms & Number of cases \\
\hline Dyspnea & 122 \\
Cough & 114 \\
Headache & 64 \\
Fever & 30 \\
Chest pain & 11 \\
Vomiting & 11 \\
Weakness & 9 \\
Body ache & 5 \\
Giddiness & 5 \\
\hline
\end{tabular}

\begin{tabular}{lc}
\hline Table 4: Pulse rate of the study participants \\
\hline Pulse & Number of cases \\
\hline$\leq 100$ & 49 \\
$101-120$ & 60 \\
$121-140$ & 34 \\
$141-160$ & 8 \\
\hline
\end{tabular}

\begin{tabular}{lc}
\hline Table 5: Oxygen saturation of the study participants \\
\hline $\mathrm{Sp}_{2}$ & Number of cases \\
\hline$\leq 50$ & 4 \\
$51-60$ & 10 \\
$61-70$ & 30 \\
$71-80$ & 72 \\
$81-90$ & 34 \\
$91-100$ & 1 \\
\hline
\end{tabular}

leukocytosis even in the absence of raised temperature. The hemoglobin was between 14 and $16 \mathrm{~g} / 100 \mathrm{ml}$ in most cases. The percentage did not show any appreciable change with recovery.

\section{Radiologic findings}

It was seen that radiologic shadows were often much more extensive than the extent of physical signs had suggested clinically. Even in a case seen early, there were woolly opacities in both the lungs in the upper and middle zones. The earliest change radiologically detected in a case, in which florid pulmonary edema later developed was fuzziness of the vascular shadows in the right middle zone. Shadows were invariably more marked on the right side. In a few cases, there were woolly shadows distributed equally throughout both lung fields. The pulmonary conus was occasionally prominent [Figures 1 and 2].

\section{Complications}

Various complications can occur or it may be coexisting conditions with HAPE:

a. Pneumonitis can predispose to HAPE or it can develop secondary to pulmonary edema. Fever $>38.5^{\circ} \mathrm{C}$ with chills and cough with purulent sputum suggest infection requiring antibiotics 
Singh, et al:: High-altitude pulmonary edema: Update from Western Himalayas

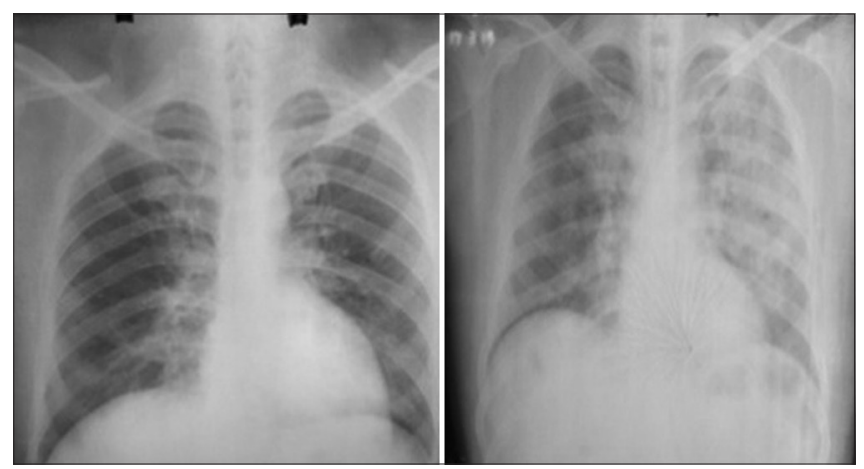

Figure 1: Area of nonhomogeneous opacities with perihilar predominance seen in both lung fields suggestive of pulmonary edema

b. Encephalopathy may develop secondary to extreme hypoxemia of HA

c. Various conditions such as pulmonary embolism, pulmonary infarction, and myocarditis have been detected at autopsy. The hallmark of these conditions is pleuritic pain and hemoptysis

d. Acute fulminant edema lasting only a few hours and ending in death can occur in a small number of cases. ${ }^{[8]}$ whether this represents an atypical course of the basic illness or a complication is unclear.

\section{Biochemical assessment of high-altitude pulmonary edema}

In the face of clinical features and radiological features, the diagnosis of HAPE was not a problem. However, the dilemma was there on rare occasions and required us to distinguish it from other diseases. HAPE most commonly is confused with pulmonary embolism at HA in terms of clinical picture; hence, objective testing is required to distinguish. ${ }^{[9,10]}$ The gold standard test for the diagnosis of pulmonary thromboembolism (PTE) is pulmonary angiography but being an invasive procedure cannot be performed in patients with clinically suspected PTE. In such suspected cases, radionuclide ventilation and perfusion lung scanning are useful, ${ }^{[11]}$ but it is frequently inconclusive. Another important test for such dilemma is the use of D-dimers to diagnose PTE. Recently, studies have reported high levels of D-dimers, using latex agglutination assays and enzyme-linked immunosorbent assays in PTE. ${ }^{[12]}$

Climbers at high heights who stay for a considerable length of time have a few hazard factors for thrombosis. They are at risk of thrombosis inlcuding pulmonary thrombo-embolism (PTE), cerebral venous thrombosis, portal/splenic vein thrombosis, and deep vein thrombosis. Out of these conditions, PTE is a very common and profoundly deadly condition that is a main source of death in all age groups. A qualified clinician will consistently attempt to rule out if there is any suspicion of PTE, in light of the fact that expeditious diagnosis and treatment can significantly diminish the death rate and morbidity of the illness. Tragically, the finding is missed more frequently than it is made, on the grounds that PTE

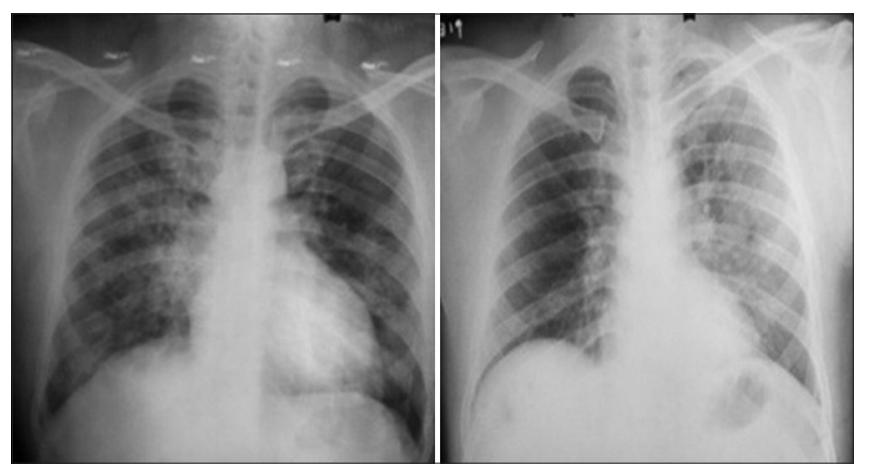

Figure 2: There is complete resolution of nonhomogeneous opacities in both lung fields

regularly causes just unclear and vague symptoms. Hence, D-dimer test, being very accurate is massively useful in the diagnosis of PTE. ${ }^{[13]}$ It can easily rule out PTE as the negative predictive value of $\mathrm{D}$-dimer is excellent. ${ }^{[14]}$ The issue with this test is the high incidence of false positives. In view of this, elevated D-dimers (above normal) in patient is considered significant and he must be followed up with a corroborative examination as well as confirmatory imaging studies. In HA sickness where PTE moderately is slightly more common, the positive predictive value of D-dimer is very high. In the present study which was conducted at HA, whenever the army troops presented with dyspnea, tachycardia, and chest pain, they could have either HAPE or PTE. In such a scenario, the D-dimer test followed by two-dimensional echocardiogram were done to rule out PTE. Patients with negative D-dimers have a high probability of having HAPE rather than PTE. Hence, this simple test helps in differentiating HAPE and PTE.

\section{Therapeutic management of high-altitude pulmonary edema}

The present study used the hospital protocol for treating majority of the HAPE patients, which was bed rest, oxygen inhalation at $5 \mathrm{~L} / \mathrm{min}$, and tablet nifedipine $30 \mathrm{mg}$ SR BD. All the patients showed a good recovery within 5-7 days. In some of the patients, positive airway pressure (CPAP) and dexamethasone were also used, which had variable results.

HAPE patients are treated routinely with oxygen/nifedipine, dexamethasone, but recently, newer modalities of treatment such as tadalafil, CPAP, and budecort have been tested. All these newer modalities have very encouraging results but will require a well-designed randomized clinical trial to be incorporated in the mainstream of treatment. There is a lack of evidence on therapeutic modalities such as defining bed rest, dose/duration of supplemental oxygen, duration of pharmacotherapy, and outcome measures. Nifedipine is recommended in the absence of supplemental oxygen and descent by the study by Oelz et al. They studied six patients at $4559 \mathrm{~m}$ and found that, despite continuing exertion, these patients showed clinical improvement with nifedipine, which also was instrumental in decreasing pulmonary hypertension 
and reducing hypoxemia in patients with HAPE in the absence of oxygen or descent. ${ }^{[15]}$

The inference by Oelz et al. was challenged by a study by Deshwal et al. ${ }^{[16]}$ who compared the efficacy of nifedipine to placebo in patients managed with a descent to a lower altitude $(1370 \mathrm{~m})$ and supplemental oxygen and failed to show any statistically significant benefit of nifedipine. The lack of information in this article about the comparison of baseline and outcome parameters between groups, as well as the method of randomization, precludes a critical evaluation of these data. Furthermore, no other studies have validated this finding. According to WMS guidelines 2014 Update, dexamethasone has a Grade $2 \mathrm{C}$ recommendation for the treatment of HAPE. ${ }^{[17]}$ Dexamethasone acts by decreasing pulmonary inflammation and enhancing epithelial ion-transport mechanisms, hence causing alveolar fluid reabsorption. ${ }^{[18]}$ It has also been found to improve maximum exercise capacity in HAPE-susceptible individuals prophylactically treated with dexamethasone. ${ }^{[19]}$ In spite of these physiological investigations exhibiting its role in HAPE prevention, there are no clinical studies indicating its advantage in proven HAPE aside from reports and case series. ${ }^{[2]}$ Furthermore, there are no guidelines on the exact dosing of dexamethasone in patients with proven HAPE. ${ }^{[17]}$ Altitude descent and oxygen remain the cornerstones of HAPE management as recorded in recent WMS guidelines. ${ }^{[21]}$ Various studies have authenticated that HAPE patients can clinically improve with bed rest alone, addition of oxygen can slightly hasten the recovery. ${ }^{[22,23]}$ Although there are various medications such as phosphodiesterase inhibitors, dexamethasone, salmeterol, and acetazolamide for the prevention of HAPE, none of the above drugs have been established for treating HAPE. Nifedipine has been accepted by current management guidelines because of its extensive use as adjunctive therapy, but other medications are discouraged by WMS. ${ }^{[21]}$ One randomized, double-blind, placebo-controlled study using both tadalafil and dexamethasone shows that both the drugs can be used to reduce the incidence of HAPE by reducing systolic pulmonary artery pressure in adults with previous history of HAPE. They used prophylactic tadalafil $(10 \mathrm{mg})$, dexamethasone $(8 \mathrm{mg})$, or placebo twice daily during ascent and stay at $4559 \mathrm{~m} \cdot{ }^{[24]}$ Another was an open-label study of tadalafil $20 \mathrm{mg}$ qd and acetazolamide $125 \mathrm{mg}$ bid versus acetazolamide $125 \mathrm{mg}$ bid for the prevention of severe HA illnesses in healthy trekkers climbing Mt. Kilimanjaro. Both intervention and control groups began study medication on day $3{ }^{[25]}$ The carbonic anhydrase inhibitor acetazolamide is the mainstay for the prevention and treatment of acute mountain sickness (AMS) and high-altitude cerebral edema. Research studies in several animals ${ }^{[26,27]}$ and the single study in humans have shown that acetazolamide prevents hypoxic pulmonary vasoconstriction and may play a role preventing HAPE, ${ }^{[28]}$ but in the absence of studies demonstrating a prophylactic effect in HAPE, it cannot be recommended for this purpose at this time. The therapeutic strategy of
HAPE has visualized a $360^{\circ}$ change from descent to low altitude, hyperbaric chamber to oxygen supplementation, nifedipine and dexamethasone to newer modalities such as CPAP, tadalfil, and budecort. The newer modalities are still in experimental stages to be included in treatment guidelines due to the lack of robust randomized clinical trials.

\section{Conclusion}

The understanding of HAPE has changed in recent times in the field of diagnosis, pathophysiology, complications, and therapeutic modalities. This update will help in opening up of new vistas of research on acute sickness at high altitudes.

\section{Financial support and sponsorship}

Nil.

\section{Conflicts of interest}

There are no conflicts of interest.

\section{REFERENCES}

1. Dumont L, Mardirosoff C, Tramer MR. Efficacy and harm of pharmacological prevention of acute mountain sickness: Quantitative systemic review. BMJ 2000;321:267-72.

2. Sartori C, Allerman Y, Duplain H, Lepori M, Egli M, Lipp E, et al. Salmeterol for the prevention of high altitude pulmonary oedema. N Engl J Med 2002;346:1631-6.

3. Basnyat B, Subedi D, Sleggs J, Lemaster J, Bhasyal G, Aryal B, et al. Disoriented and ataxic pilgrims: An epidemiological study of acute mountain sickness and high-altitude cerebral edema at a sacred lake at $4300 \mathrm{~m}$ in the Nepal Himalayas. Wilderness Environ Med 2000;11:89-93.

4. Menon ND. High-altitude pulmonary edema: A clinical study. N Engl J Med 1965;273:66-73.

5. Singh I, Kapila CC, Khanna PK, Nanda RB, Rao BD. High-altitude pulmonary oedema. Lancet 1965;1:229-34.

6. Hultgren HN, Marticorena EA. High altitude pulmonary edema. Epidemiologic observations in Peru. Chest 1978;74:372-6.

7. Director General Armed Forces Medical Services. Problems of High Altitude. New Delhi: Director General Armed Forces Medical Services; 1997. Memorandum 140.

8. Hackett PH, Roach RC, Schoene RB, Harrison GL, Mills JW. Abnormal control of ventilation in high-altitude pulmonary edema. J Appl Physiol 1988;64:1268-72.

9. Hull RD, Raskob GE, Carter CJ, Coates G, Gill GJ, Sackett DL, et al. Pulmonary embolism in outpatients with pleuritic chest pain. Arch Intern Med 1988;148:838-44.

10. Bell WR, Simon TL, DeMets DL. The clinical features of submassive and massive pulmonary emboli. Am J Med 1977;62:355-60.

11. Hull RD, Hirsh J, Carter CJ, Jay RM, Dodd PE, Ockelford PA, et al. Pulmonary angiography, ventilation lung scanning, and venography for clinically suspected pulmonary embolism with abnormal perfusion lung scan. Ann Intern Med 1983;98:891-9.

12. Bounameaux H, Slosman D, de Moerloose P, Reber G. Laboratory diagnosis of pulmonary embolism: Value of increased levels of plasma D-dimer and thrombin-antithrombin III complexes. Biomed Pharm Uother 1989;43:385-88.

13. Heit JA, Minor TA, Andrews JC, Larson DR, Li H, Nichols WL. Determinants of plasma fibrin D-dimer sensitivity for acute pulmonary embolism as defined by pulmonary angiography. Arch Pathol Lab Med 1999; $123: 235-40$.

14. Kearon C, Ginsberg JS, Douketis J, Turpie AG, Bates SM, Lee AY, et al. An evaluation of D-dimer in the diagnosis of pulmonary embolism: A randomized trial. Ann Intern Med 2006;144:812-21.

15. Oelz O, Maggiorini M, Ritter M, Waber U, Jenni R, Vock P, et al. 
Nifedipine for high altitude pulmonary oedema. Lancet 1989;2:1241-4.

16. Deshwal R, Iqbal M, Basnet S. Nifedipine for the treatment of high altitude pulmonary edema. Wilderness Environ Med 2012;23:7-10.

17. Luks AM, McIntosh SE, Grissom CK, Auerbach PS, Rodway GW, Schoene RB, et al. Wilderness Medical Society practice guidelines for the prevention and treatment of acute altitude illness: 2014 update. Wilderness Environ Med 2014;25:S4-14.

18. Urner M, Herrmann IK, Booy C, Roth-Z' Graggen B, Maggiorini M, Beck-Schimmer B. Effect of hypoxia and dexamethasone on inflammation and ion transporter function in pulmonary cells. ClinExp Immunol 2012;169:119-28.

19. Siebenmann C, Bloch KE, Lundby C, Nussbamer-Ochsner Y, Schoeb M, Maggiorini M. Dexamethasone improves maximal exercise capacity of individuals susceptible to high altitude pulmonary edema at $4559 \mathrm{~m}$. High Alt Med Biol 2011;12:169-77.

20. Jones BE, Stokes S, McKenzie S, Nilles E, Stoddard GJ. Management of high altitude pulmonary edema in the Himalaya: A review of 56 cases presenting at Pheriche medical aid post $(4240 \mathrm{~m})$. Wilderness Environ Med 2013;24:32-6.

21. Luks AM, McIntosh SE, Grissom CK, Auerbach PS, Rodway GW, Schoene RB, et al. Wilderness Medical Society consensus guidelines for the prevention and treatment of acute altitude illness. Wilderness Environ Med 2010;21:146-55.
22. Marticorena E, Hultgren HN. Evaluation of therapeutic methods in high altitude pulmonary edema. Am J Cardiol 1979;43:307-12.

23. Zafren K, Reeves JT, Schoene R. Treatment of high-altitude pulmonary edema by bed rest and supplemental oxygen. Wilderness Environ Med 1996;7:127-32.

24. Maggiorini M, Brunner-La Rocca H, Peth S, Fischler M, Böhm T, Bernheim A, et al. Both Tadalafil and dexamethasone may reduce the incidence of high-altitude pulmonary edema. Ann Int Med 2006;145:497.

25. Leshem E, Caine Y, Rosenberg E, Maaravi Y, Hermesh H, Schwartz E. Tadalafil and acetazolamide versus acetazolamide for the prevention of severe high-altitude illness. J Travel Med 2012;19:308-10.

26. Höhne C, Krebs MO, Seiferheld M, Boemke W, Kaczmarczyk G, Swenson ER. Acetazolamide prevents hypoxic pulmonary vasoconstriction in conscious dogs. J Appl Physiol (1985) 2004;97:515-21.

27. Höhne C, Pickerodt PA, Francis RC, Boemke W, Swenson ER Pulmonary vasodilation by acetazolamide during hypoxia is unrelated to carbonic anhydrase inhibition. Am J Physiol Lung Cell Mol Physiol 2007;292:L178-84.

28. Teppema LJ, Balanos GM, Steinback CD, Brown AD, Foster GE, Duff HJ, et al. Effects of acetazolamide on ventilatory, cerebrovascular, and pulmonary vascular responses to hypoxia. Am J Respir Crit Care Med 2007;175:277-81. 